\title{
CFD MODELING AND SIMULATION OF AN INDUSTRIAL HALL
}

\author{
Florin-Bogdan MARIN, Mihaela MARIN \\ "Dunarea de Jos" University of Galati, Romania \\ e-mail: flmarin@ugal.ro,mihaela.marin@ugal.ro
}

\begin{abstract}
The subject of this research is the use of artificial vision techniques to optimize the placement of hot air sources depending on the location of certain equipment in industrial halls operating at low temperatures. Low temperature industrial halls require optimization of the location of hot air sources to achieve low consumption and efficient heating, taking into account the fact that workplace safety standards require the halls are high and at a certain area of windows (to ensure a hall for this reason, it is necessary to optimize the location and hot air sources flow to ensure the heating of these halls.
\end{abstract}

KEYWORDS: CFD, modeling, simulation, industrial hall

\section{Introduction}

Computational fluid dynamics (CFD) is a part of the mechanics of having fluids different numerical methods and computational algorithms used by computers for determining the various problems related to the flow of fluids in various fields [1-22]. Programs often used in industry that are based on C.F.D. are: Ansys, OpenFoam, XFlow, Star-CCM +, Flow-3D, FloWorks, Autodesk Simulation CFD, Solidworks CFD Simulation. The mentioned programs present various calculation methods, each having their advantages and disadvantages, the main factors affecting the data obtained are based on discretization and calculation methods integrated in programs.

CFD modeling is based on the principles of fluid mechanics, to solve problems that involve fluid flows numerical methods and algorithms approach are used. The basic idea in the finite element method is to find the solution to a complicated problem by replacing it with a simpler one. The finite element method has emerged as a consequence of the need to calculate complex strength structures for which analytical calculation methods are not operable. The main idea is that a structure is divided into several parts called "finite elements" for each of them can be applied the calculation theories corresponding to the scheme adopted (bar theory, plate or solid). Dividing the whole into smaller parts, an operation that bears the well-known name of "discretization" will have the effect of obtaining simple shapes for the finite elements' components of the structure.
In order to perform a CFD simulation, four important steps are required: 1 - C.F.D. domain analysis/fluid in which the virtual model will be introduced, 2 - discretization of the fluid domain by various methods to determine the pressure gradient at different calculation points, 3 - setting flow conditions, fluid parameters, turbulence patterns, and another conditions to be able to start the aerodynamic calculation, 4 - aerodynamic analysis of the result is performed, as well as a change of the physical conditions previously used in case of the virtual model. The main programs based on dynamic fluid calculation use the same calculation methods and algorithms.

Low temperature industrial halls require hot air optimization location of sources to achieve low consumption and efficient heating, taking into account the fact that workplace safety standards require high halls and at a certain area of windows. For this reason, it results that the windows have a relatively poor insulation, it is necessary to optimize the location and hot air flow to ensure the halls heating. Using several CFD simulations, which allow to calculate with a very good accuracy the way heat, air currents circulate in the air, we want to train a neural network that will allow intelligent control of the heating system by estimating the optimal positioning of air sources. This optimization is necessary because some tools with considerable volume in the hall are fixed but other components of the industrial flow, such as temporary processing machines or trucks (which can park for hours or days) can influence the heating of the industrial hall operating at low temperatures [23-28]. The neural 


\section{THE ANNALS OF “DUNAREA DE JOS” UNIVERSITY OF GALATI \\ FASCICLE IX. METALLURGY AND MATERIALS SCIENCE \\ $\mathrm{N}^{\circ} .4$ - 2021, ISSN 2668-4748; e-ISSN 2668-4756 \\ Article DOI: https://doi.org/10.35219/mms.2021.4.15}

network manages to estimate the location of the heat source quite well. Further developments should also include parameters such as the distance to objects with high volume and the variability of these volumes.

\section{Experimental procedure}

The aim of this research is the use of artificial vision techniques in order to optimize the placement heat sources considering: i) the location of equipment in industrial halls operating at low temperatures, ii) relative high height of industrial hall, iii) considerable percent of glass because of safety standards concerning explosion and fire. Consequently, low temperature industrial halls require optimization of the location of hot air sources to achieve low consumption and efficient heating. For this reason, it is necessary to optimize the location and hot air sources flow to ensure the heating of these halls. The simulations on an industrial la a hall was executed. The simulations consider a heating system and a cold air flow of from outside.

The purpose of this paper is to determines if the location, as well as the heating system power allow the heating of the hall in extremes temperature conditions. The industrial hall is considered to be made of steel without any additional thermal insulation. The simulations with the following initial conditions were done: outdoor temperature: -10 degrees, radiator temperature: 80 degrees, inlet flow and outlet flow: $0.3 \mathrm{~m}^{3} / \mathrm{s}$.

\section{Results and discussions}

As seen in Fig. 1 and Fig. 2 often happens in real case scenarios when high volume in the hall such as products or trucks change the way the air is circulating in the hall. Following the experiments performed using the Open Foam program, the trajectories of the air currents have the trajectories presented in Fig. 3 and Fig. 4. It is observed that there is a movement of the air currents from the heat source to the ceiling, where the air mass is colder. There is also a disordered and non-optimized motion in 3D space.

As seen in Fig. 5 and Fig. 6 in case of unoptimized placement of heating source in respect to the other objects, the heating distribution is not efficient. There is a difference of even 10 degrees between different areas of the industrial hall. A neural network is trained using 30 simulations in order to determine optimal placement of heating for an industrial hall.

The neural network needs to output 2D coordinates of heating source taking into account the volumes in the hall, both temporary and permanent. The trained network architecture consisted of 10 hidden layers. The results show good temperature estimation, as the network was able to predict with a precision of $91 \%$.

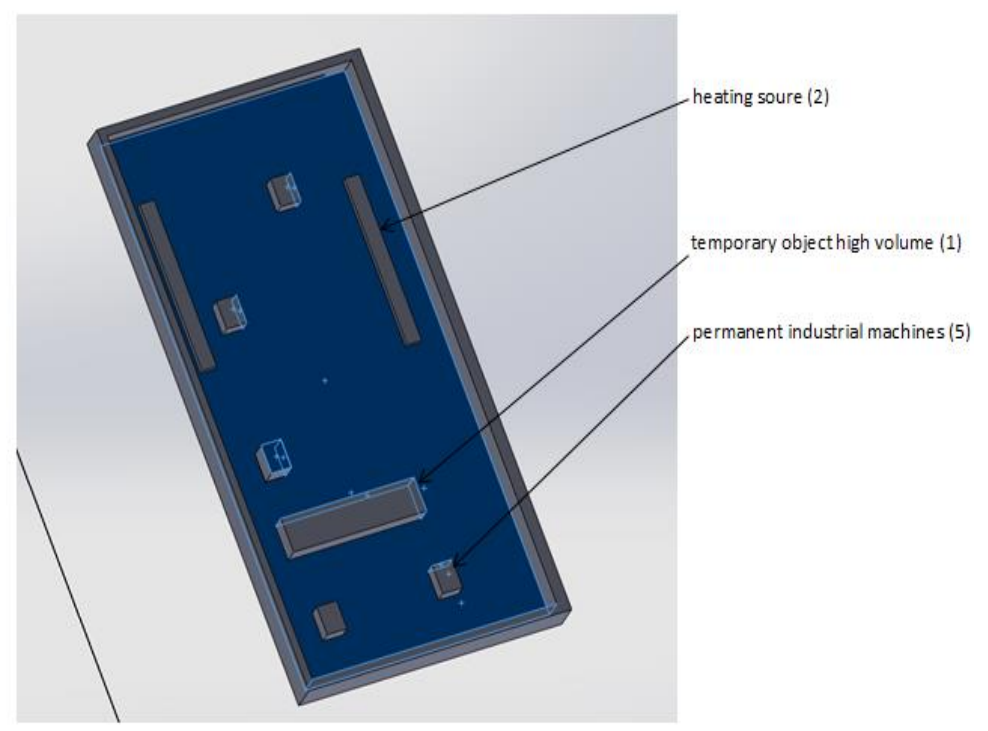

Fig. 1. Scenario of placement 
THE ANNALS OF "DUNAREA DE JOS" UNIVERSITY OF GALATI

FASCICLE IX. METALLURGY AND MATERIALS SCIENCE

$\mathrm{N}^{\circ} .4$ - 2021, ISSN 2668-4748; e-ISSN 2668-4756

Article DOI: https://doi.org/10.35219/mms.2021.4.15

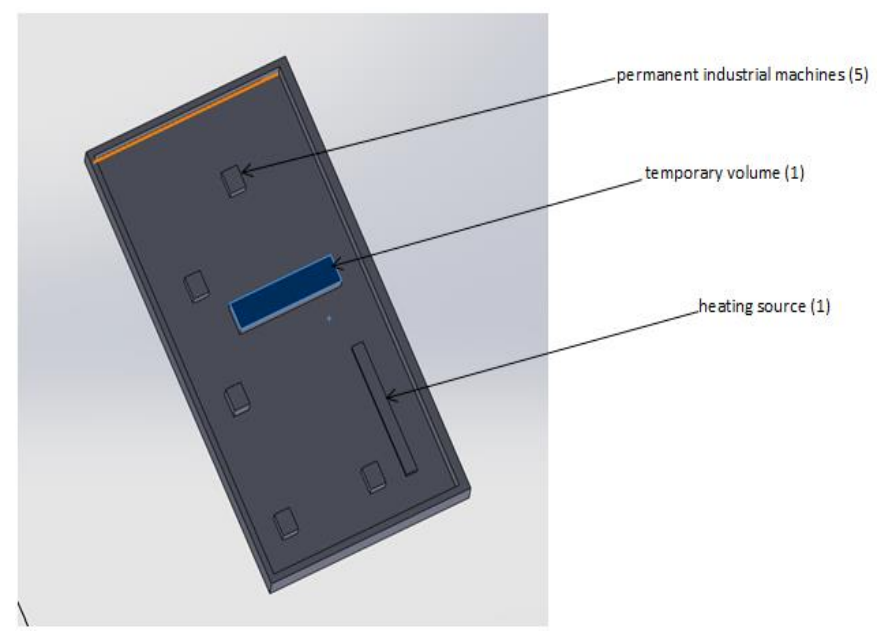

Fig. 2. One of the scenarios of placement

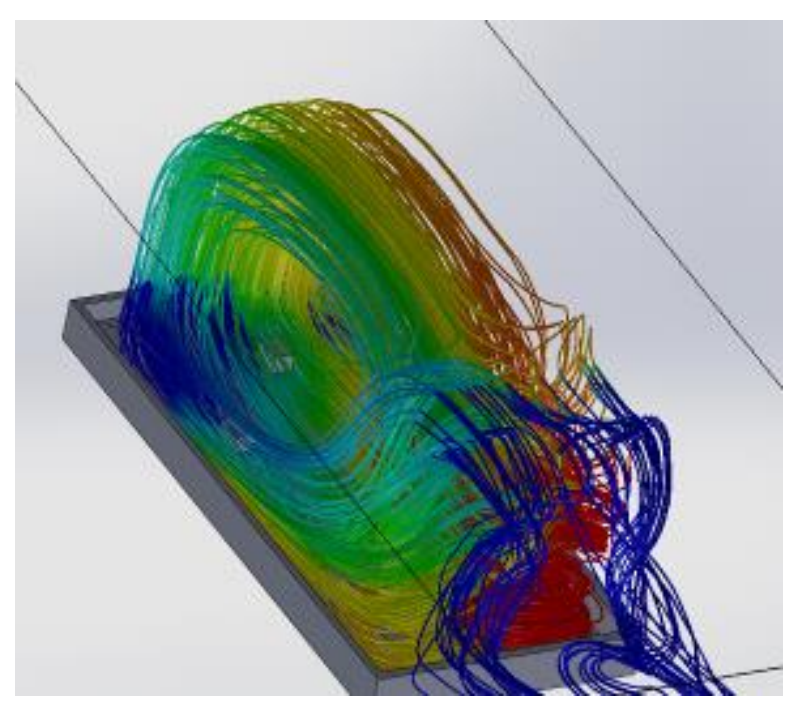

Fig. 3. Air circulation

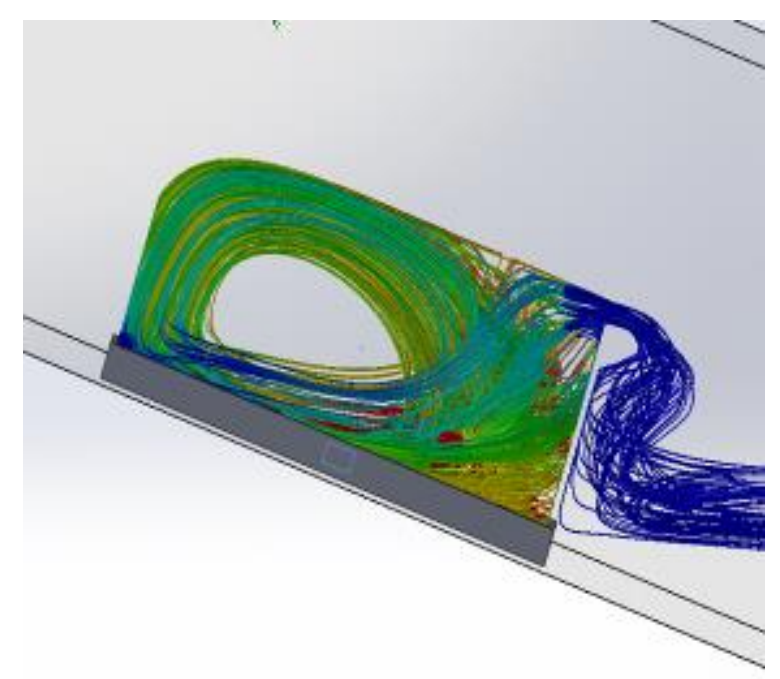

Fig. 4. Air circulation 


\section{THE ANNALS OF “DUNAREA DE JOS” UNIVERSITY OF GALATI \\ FASCICLE IX. METALLURGY AND MATERIALS SCIENCE \\ $\mathrm{N}^{\circ} .4$ - 2021, ISSN 2668-4748; e-ISSN 2668-4756 \\ Article DOI: https://doi.org/10.35219/mms.2021.4.15}

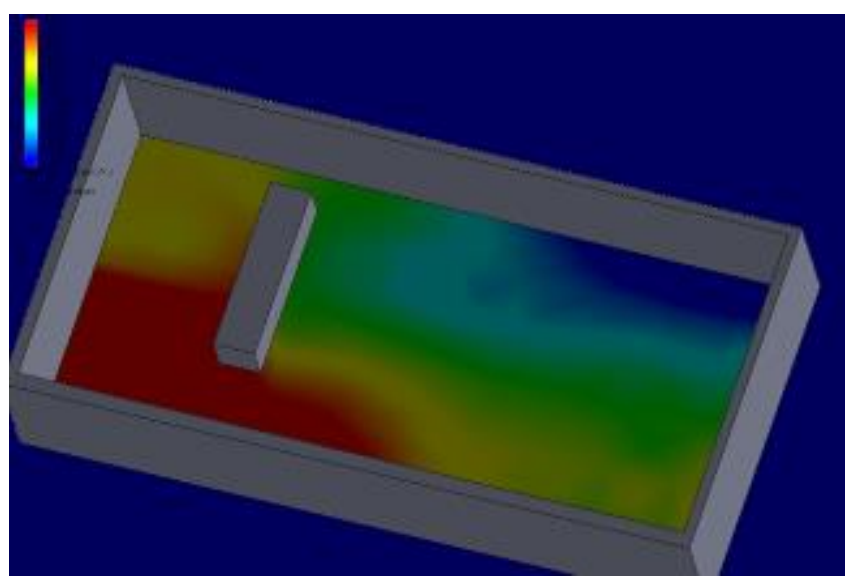

Fig. 5. Heating variation of the fluid (air) in a horizontal plane placed at 2.5 meter above ceiling

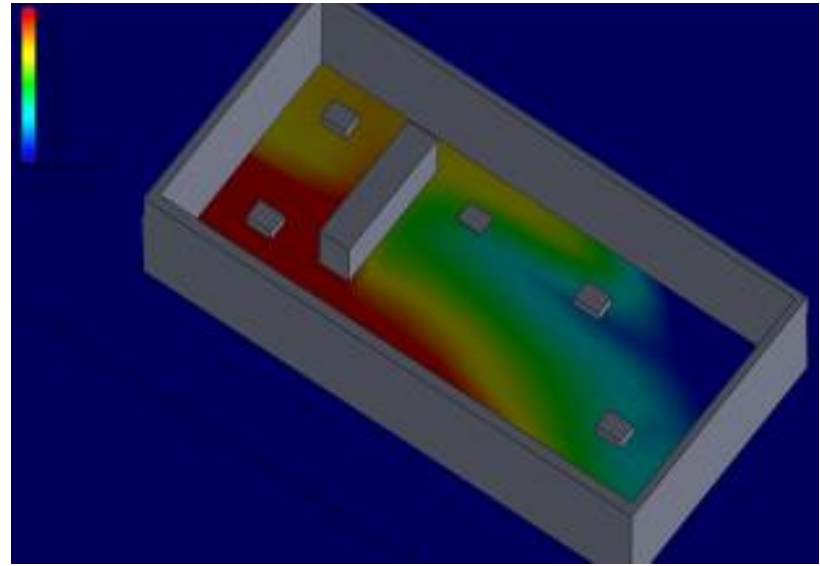

Fig. 6. Heating variation of the fluid (air) in a horizontal plane placed at 0.5 meter above ceiling

\section{Conclusions}

The neural network manages to estimate the location of the heat source quite well. Further developments should also include parameters such as the distance to objects with high volume and the variability of these volumes.

The neuronal network will allow a better approximation in case of training a larger number of samples.

\section{References}

[1]. Tanasic N., Jankes G., Skistad H., CFD analysis and airflow measurements to approach large industrial halls energy efficiency: A case study of a cardboard mill hall, Energy and Buildings, vol. 43, issue 6, p. 1200-1206, 2011.

[2]. Fujii K., Progress and future prospects of CFD in aerospaceWind tunnel and beyond, Progress in Aerospace Sciences, vol. 41, issue 6, p. 455-470, ISSN 0376-0421, 2005.

[3]. Xia H., Tucker P. G., Dawes W. N., Level sets for CFD in aerospace engineering, Progress in Aerospace Sciences, vol. 46, issue 7, p. 274-283, ISSN 0376-0421, 2010.

[4]. Wang C., Li F., Ding Z., Zhang L., Numerical Simulation of Hypersonic Flow Around an Aerospace Plane by Parallel RANS based CFD, Procedia Engineering, vol. 61, p. 23-27, ISSN 18777058, 2013

[5]. Danca P., Bode F., Nastase I., Meslem A., On the Possibility of CFD Modeling of the Indoor Environment in a Vehicle, Energy Procedia, vol. 112, p. 656-663, 2017.

[6]. Gosman A. D., Developments in CFD for industrial and environmental applications in wind engineering, Journal of Wind Engineering and Industrial Aerodynamics, vol. 81, Issues 1-3, p. 21-39, ISSN 0167-6105, 1999.

[7]. Kohler H., Liebmann V., Golla C., Frohlich J., Rudiger F., Modeling and CFD-simulation of cleaning process for adhesively detaching film-like soils with respect to industrial application, Food and Bioproducts Processing, vol. 129, p. 157-167, ISSN 0960-3085, 2021.

[8]. Ghaffari M., Hoffmann A., Skjold T., Rolf K., Eckhoff K., Wingerden, A brief review on the effect of particle size on the laminar burning velocity of flammable dust: Application in a CFD tool for industrial applications, Journal of Loss Prevention in the Process Industries, vol. 62, 103929, ISSN 0950-4230, 2019.

[9]. Aksenov A. A., Kharchenko S. A., Konshin V. N., Pokhilko V. I., FlowVision software: Numerical simulation of industrial CFD applications on parallel computer systems, Parallel Computational Fluid Dynamics, p. 401-408, ISBN 9780444516121, 2003.

[10]. Pavan K. Sharma, Modeling of fire with CFD for nuclear power plants (NPPs), Advances of Computational Fluid Dynamics in Nuclear Reactor Design and Safety Assessment, p. 663-727, 2019.

[11]. Berni F., Cicalese G., Borghi M., Fontanesi S., Towards grid-independent $3 D$-CFD wall-function-based heat transfer 


\section{THE ANNALS OF “DUNAREA DE JOS” UNIVERSITY OF GALATI \\ FASCICLE IX. METALLURGY AND MATERIALS SCIENCE \\ $\mathrm{N}^{\circ} .4$ - 2021, ISSN 2668-4748; e-ISSN 2668-4756 \\ Article DOI: https://doi.org/10.35219/mms.2021.4.15}

models for complex industrial flows with focus on in-cylinder simulations, Applied Thermal Engineering, vol. 190, 116838, ISSN 1359-4311, 2021.

[12]. Tutar M., Ustun C., Campillo-Robles J. M., Fuente R., Cibrian S., Arzua I., Fernandez A., Lopez G., Optimized CFD modelling and validation of radiation section of an industrial topfired steam methane reforming furnace, Computers \& Chemical Engineering, vol. 155, 107504, ISSN 0098-1354, 2021.

[13]. Rizzi A., Jluckring J. M., Historical development and use of CFD for separated flow simulations relevant to military aircraft, Aerospace Science and Technology, vol. 117, 106940, ISSN 12709638, 2021.

[14]. Wang M., Wang Y., Tian W., Qiu S., Su G. H., Recent progress of CFD applications in PWR thermal hydraulics study and future directions, Annals of Nuclear Energy, vol. 150, 107836, ISSN 0306-4549, 2021.

[15]. Seshaiah T., Vasu B., Vijaya K., Reddy K., Bridjesh P. Analysis on aircraft winglet at different angles by using CFD simulation, Materials Today: Proceedings, ISSN 2214-7853, 2021.

[16]. Garcia-Ribeiro D., Flores-Mezarina J. A., BravoMosquera P. D., Cerón-Muñoz H. D., Parametric CFD analysis of the taper ratio effects of a winglet on the performance of $a$ Horizontal Axis Wind Turbine, Sustainable Energy Technologies and Assessments, vol. 47, 101489, ISSN 2213-1388, 2021.

[17]. Zhu X, Dai Y., Ma F., CFD modelling and numerical simulation on windage power loss of aeronautic high-speed spiral bevel gears, Simulation Modelling Practice and Theory, vol. 103, 102080, ISSN 1569-190X, 2020.

[18]. Zobaer T., Sutradhar A., Modeling the effect of tumor compression on airflow dynamics in trachea using contact simulation and CFD analysis, Computers in Biology and Medicine, vol. 135, 104574, ISSN 0010-4825, 2021.

[19]. Perinajov R., Juffermans J., Westenberg J. M., Roel L.F., Palen Pieter J. Boogaard, Hildo J. Lamb, Sas a Kenjeres, Geometrically induced wall shear stress variability in CFD-MRI coupled simulations of blood flow in the thoracic aortas, Computers in Biology and Medicine, vol. 133, 104385, ISSN 00104825, 2021.
[20]. Shoeibi S., Kargarsharifabad H., Rahbar N., Ahmadi G., Reza M. S., Performance evaluation of a solar still using hybrid nanofluid glass cooling-CFD simulation and environmental analysis, Sustainable Energy Technologies and Assessments, vol. 49, 101728, ISSN 2213-1388, 2022.

[21]. Norton T., Sun D., Computational fluid dynamics (CFD) an effective and efficient design and analysis tool for the food industry: A review, Trends in Food Science \& Technology, vol. 17, Issue 11, p. 600-620, 2006.

[22]. Wutz J., Waterkotte B., Heitmann K., Wucherpfennig T., Computational fluid dynamics (CFD) as a tool for industrial UF/DF tank optimization, Biochemical Engineering Journal, vol. 160, 107617, ISSN 1369-703X, 2020.

[23]. Silvestri L., CFD modeling in Industry 4.0: New perspectives for smart factories, Procedia Computer Science, vol. 180, p. 381387, ISSN 1877-0509, 2021.

[24]. Lim J., Ooka R., A CFD-Based Optimization of Building Configuration for Urban Ventilation Potential, Energies, 14, 1447, 2021

[25]. Souza C., Kurka P., Lins R., Araujo J., Performance comparison of non-adaptive and adaptive optimization algorithms for artificial neural network training applied to damage diagnosis in civil structures, Applied Soft Computing, vol. 104, 107254, ISSN 1568-4946, 2021.

[26]. Volker D., Lindner M., Weigold M., Design Method for Building Automation Control Programs to Enable the Energetic Optimization of Industrial Supply Systems, Procedia CIRP, vol. 104, p. 229-234, ISSN 2212-8271, 2021.

[27]. Si B., Wang J., Yao X., Shi X., Jin X., Zhou X., Multiobjective optimization design of a complex building based on an artificial neural network and performance evaluation of algorithms, Advanced Engineering Informatics, vol. 40, p. 93-109, ISSN 1474-0346, 2019.

[28]. Iijima F., Ikeda S., Nagai T., Automated computational design method for energy systems in buildings using capacity and operation optimization, Applied Energy, vol. 306, Part A, 117973 , ISSN 0306-2619, 2022 